九州大学学術情報リポジトリ

Kyushu University Institutional Repository

A test of the hypothesis of economic rationality in the mechanization of small scale farming in Japan

Tsuchiya, Ke izo

Laboratory of Quantitative Analysis of Agricultural Economics, Department of Agriculture, Kyushu University

https://doi.org/10.5109/22808

出版情報: 九州大学大学院農学研究院紀要. 16 (4), pp. 339-348, 1971-11. Kyushu University バージョン：

権利関係 : 
Journal of the Faculty of Agriculture, Kyushu University, Vol. 16, No. 4 November 30, 1971

\section{A test of the hypothesis of economic rationality in the mechanization of small scale farming in Japan*}

\section{Keizo TSUCHIYA}

\section{Introduction}

In this paper it will be our objective to study the economics of mechanization in small scale farming in Japan, In 1931 there were only about 100 power tillers, in 1937 there were approximately 1,000, but with rapid expansion, the number rose to 89,000 in 1955 and by 1965 there were some $2,500,000$ power tillers in Japanese farms. In Japan exports of farm machinery are still very limited in comparison with total production. The major portion is distributed for domestic use. In as much as power tillers constitute 56 per cent of the total farm machinery produced, it can be said that the mechanization of Japanese agriculture has been mainly represented by power tillers.

We must mention, however, that the process of mechanization of Japanese agriculture is different from that of Western countries. First, the mechanization in Western countries was in upland fields, where es in Japan it was seen mainly in paddy fields. The 1964 survey showed that the fraction of area cultivated by mechanical power was 78.6 and 29.0 per cent in paddy and in upland fields, respectively (Ministry of Agriculture and Forestry, 1965). Secondly, mechanization in Western countries has applied to the whole range of field operations, but in Japan this has not been the case. Power tillers, the main machinery in Japanese agriculture, have not been utilized throughout the processes of cultivation, but have been restricted to such processes as tillage, breaking of clods, levelling, and puddling. Rice trans-

\footnotetext{
* An earlier draft of this paper was presented at the Second World Congress of the Econometric Society, Cambridge, England, September 8-14, 1970. The author is greatly indebted to Professor S. Sawada and Mr. John Edward Zwyghuizen. Also part of this paper is based on the article by Keizo Tsuchiya, Economics of Mechanization in Small Scale Agriculture, Agriculture and Economic Growth : Japan's Experience, K. Ohkawa, B. F. Johnston and H. Kaneda, eds., 1969. Tokyo University Press and Princeton University Press.
} 
planting and rice harvesting have not been mechanized so that a great deal of labor is still required for these processes. Thirdly, the mechanization in Western countries increased the yield of farm products. However, the results of research done by agricultural experimental stations of prefectural governments in Japan show that the introduction of power tillers did not increase the yield of farm products such as rice and wheat. Fourthly, the estimated horsepower of draft animals has decreased rapidly since 1955 because of the introduction of power machinery which show that power tiller has been substituted for animal power and the horsepower increase in farm machinery is much faster than the horsepower decrease in draft animals. Therefore we are led to infer that the introduction of the power tiller has saved more man hours than animal power.

Because the process of mechanizing Japanese agriculture was different from that of Western countries, many Japanese authors have emphasized the behavior of the Japanese farm family which, they thought, must be different from that of industrial enterprises. Kayo has summarized these nonrational factors in the following five categories (Kayo, 1963) : 1) Over-investment. 2) Demonstration effect. 3) The demand of young farm successors. 4) The increase in leisure time. 5) Physical stamina. As can easily be seen those studies do not deal with the introduction of power tillers as a product of the rational behavior of entrepreneurs. However the price of power tillers remains fairly expensive, and according to the Survey Report "Price and Wage Rates in Farm Villages", the price of a power tiller in 1964 amounted to approximately $¥ 190,000$ (excluding attachments). This was very high compared with the farm household income of $¥ 670,000$ and farm income of $\ 320,000$ of the same year. Furthermore, if a farmer wanted to buy a power tiller, he had to take the entire responsibility for payment. The Machinery Association made a survey of 2,061 farms in which power tillers were introduced. According to this survey, 84 per cent of the farms surveyed explained that the decrease in labor force was the main reason for the introduction of power tillers. Very few respondents cited the demonstration effect or other non-economic reasons. This raises doubts concerning the non-economic explanation of the mechanization of Japanese agriculture. Rather, it would have been more appropriate to discuss this mechanization from the viewpoint of economic factors. In what follows this paper will attempt to present a case for the economic rationality approach. 


\section{Derivation of Models}

The widest application of power tillers is found in the northeastern districts of Japan (Tohoku and Hokuriku) where rice prodction is dominant: 44 power tillers per 100 farms, whereas in the remote districts, e. g., Kyushu, only 17 power tillers per 100 farms are used.

As the distribution of power tillers and causes of mechanization differ between regions, separate models are needed for each region. In this paper, the economics of mechanization of small-scale farming in Japan will be discussed by concentrating our attention on the Tohoku district where the largest spread of power tillers is observed. The Tohoku district is a single crop area, and the construction of a model for this district is easier because rice yield per 0.1 ha. have not increased substantially, thereby eliminating the need to treat technological progress. As mentioned previously, prefectural experimental station report that there is no increase in the yield of rice resulting from the use of power tillers. In this paper, therefore, we can safely ignore the yield effect of power cultivation.

In our analysis we have assumed the following conditions : a) perfect competition in the labor and farm machinery markets, b) a constant acreage of farm land cultivated by the farmer himself, c) farm costs being equal to labor plus machinery costs, and d) change in the method of farming being limited to the substitution of machinery for labor has made no change to the net product per 0.1 ha.

Nakajima $(1958,1966)$ and Tanaka (1967) have developed the theory of utility maximization as the behavioristic principle of small-scale farming. Our model here is suggested by their works, and the behavioristic principle of the farm household is adopted to maximize the utility function

(1) $U=U(A, \mathrm{M})$, where $U_{A}<0, U_{M}>0,\left.\frac{\partial^{2} M}{\partial A^{2}}\right|_{U=\text { const. }}>0$

subject to the isoquant equation which is derived from the condition b) and d)

(2) $\mathrm{B}(\mathrm{b})=f(a, \mathrm{k})$, where $f_{a}>0, f_{k}>0, \frac{\partial^{2} a}{\partial k^{2}}>0$

and the money equation

( 3 ) $M=P_{y} \tilde{y}+W(A-a)+P_{k}(\bar{K}-k)$,

where $\tilde{y}=$ real net farm product, a=labor input in owned farm, $k=$ utilization hours of power machinery in owned farm, $\bar{b}=$ farm land, M=money income (farm household income), W=wage rate of hired worker, $P_{y}=$ 
price of y, $\mathrm{A}=$ family labor input in farm and non-farm sector, $K=$ total utilization hours of owned power machinery, $\boldsymbol{P}_{\boldsymbol{k}}=$ hourly rent for power tillers.

If $A<a$, labor is hired from another farm but if $A>a$, labor is sold to another farm. If $A<a, W(A-a)$ would be negative and would imply a wage payment. Similarly, ifK $<\mathrm{k}, P_{k} \overline{(K-k)}$ would be negative and would imply a payment of rent. If $\mathbf{K}<\mathbf{k}, P_{k}(\mathbf{K}-\mathbf{k})$ would be positive and would mean a receipt of rent. The equilibrium conditions will be as follows :

(4) $\frac{\partial f / \partial a}{\partial f / \partial k}=\frac{\mathrm{W}}{P_{k}}$

( 5 ) $W=-\frac{U_{A}}{U_{M}}$

If we take equations (2), (3),(4), and (5) simultaneously, a, A, k and $\mathbf{M}$ are obtained by taking $\mathbf{W}, P_{k}, \bar{K}$ as parameters. Here, attention should be paid to the fact that at first $\tilde{y}$ is determined by $\bar{b}$, and then $\mathrm{a}$ and $\mathbf{k}$ are determined by equations (2) and (4). Then, $\mathbf{A}$ and $\mathbf{M}$ are determined by (3) and (5).

Equation (4) is synonymous with the enterprise behavior which minimizes the production cost in order to produce a given output. Namely, if we minimize cost function,

(6) $\mathrm{C}=W_{a}+P_{k} k$

subject to equation (2), the equilibrium condition becomes

(4') $\frac{\partial f / \partial a}{\partial f / \partial k}=\frac{W}{P_{k}^{-}}$

Equations (4) and (4') are exactly the same, and the equilibrium valued of $\boldsymbol{a}$ and $\mathbf{k}$ are solved by considering equations (2) and (4) simultaneously. $\mathbf{A}$ and $\mathbf{M}$ are determined by maximizing the utility function subject to equation (3), substituting equilibrium values of $a$ and $\mathbf{k}$.

Now, as $a$ means of summarising the model mentioned above, we note that in the models where the markets for labor and machinery are perfectly competitive, the farm household minimizes the cost of production in the same way as other industrial enterprises (profit maxization of farm sector). Furthermore, the farm household maximizes the utility function based on the laborer's household. The model should be tested by the following model structure:

The isoquant equation is assumed as 
(7) $\tilde{y}=v a^{\alpha} k^{\beta}$, where $v>0, \alpha>0, \beta>0$

and the cost equation is

(8) $\mathrm{C}=W a+P_{k} k$

where $\tilde{y}=$ real net farm product, $a=$ hours of labor input in owned farm, $k=$ utilization hours of power machinery in owned farm, $\alpha, \beta$ and $\mathrm{v}=$ parameter to be estimated, $\mathrm{C}=\operatorname{cost}, \mathbf{W}=$ wage rate of hired worker, $\boldsymbol{P}_{k}=$ hourly rent for power farm machinery.

If $\bar{y}, \mathbf{W}, \boldsymbol{P}_{k}$ are taken as parameters, the equilibrium condition becomes

(9) $\left(\begin{array}{ll}\log & a \\ \log & k\end{array}\right)=\left(\begin{array}{cc}1 & 11 \\ \alpha & \beta\end{array}\right)\left(\begin{array}{l}\log W-\log P_{k}+\log \beta-\log \alpha \\ \log \tilde{y}-\log v\end{array}\right)$

\section{Empirical estimation of the models}

The equations described above were fitted to the data obtained from the Survey of Farm Household Economy for the Tohoku district. These data such as $\tilde{y}, \mathbf{a}, \mathbf{k}$ and $\mathbf{w}$ were obtained from the records of the survey and were classified according to the operating acreage spread over the eight years from 1957 to 1964 . We might note here that the number surveyed in Tohoku was 694 and that the accuracy of the survey was very high. The reason for using 1957 as the base year was that a big revision of the survey method was carried out in that year. The change in the survey method raises difficulties in establishing continuity of the data for the years before and after 1957.

However, difficult problems arose in the estimation of the hourly rent for tilling by power tillers which we have estimated as follows. The rent of power tillers per 0.1 ha. is obtained from the Survey of Farm Household Economy. The capacity of power tiller is estimated as one hour per 0.1 ha. Therefore, the hourly rent for tilling has been estimated as the rent per 0.1 ha.

The statistical results of the equation (7) are tabulated in Table 1 and the solution of equation (9) are tabulated in Table 2 and Table 3 . The upper rows in Tables 2 and 3 show actual values, and the lower rows show optimum values. The difference between actual values and optimum values in Tables 2 and 3 are small. Therefore, this model is, I believe, appropriate for explaining the actual behavioristic principle of farm households. Kudo's explanation (Kudo, 1962) also supports our results. He pointed out that "such rational behavior is seen because power tillers are so expensive. Farmers have to buy power tillers with their own funds. Because a special credit-financing system for farmers has not yet been developed, they are forced to calculate 
the economic feasibility of buying machines on their own account".

Table 1. Regression results. $y_{t}=v a_{t}^{\alpha} k_{t}^{\beta}$

\begin{tabular}{lcccc}
\hline F a r m s i z e & v & $\alpha$ & $\beta$ \\
\hline O.3-O. 5ha & 0.224930 & 0.481571 & 0.164378 \\
0.5-1. 0 & 0.212920 & 0.847337 & 0.432288 \\
1.0-1.5 & 0.072410 & 1.326090 & 0.898990 \\
1.5-Z. 0 & 0.237930 & 0.642084 & 0.456269 \\
2.0 Over & 0.214710 & 0.572090 & 0.667985 \\
\hline
\end{tabular}

Table 2. Comparison of actual and optimum hours of utilization of power farm machinery by farm size.

(unit : 10 hours)

\begin{tabular}{|c|c|c|c|c|c|c|}
\hline $\begin{array}{l}\mathrm{r}_{\text {Hours }} \mathrm{F} \\
\text { Hon }\end{array}$ & arm size & $0.3-0.5^{\prime \prime \prime}$ & $0.5-1.0 "$ & $1.0-1.5^{\mathrm{ha}}$ & $1.5-2.0^{\text {ha }}$ & $2.0^{\text {ha }}$ over \\
\hline Actual & hours & 32 & 66 & 145 & 210 & 349 \\
\hline Optimum & hours & $1^{25}$ & 66 & 137 & 184 & 356 \\
\hline
\end{tabular}

Table 3. Comparison of actual and optimum hours of farm labor by farm size.

\begin{tabular}{|c|c|c|c|c|c|}
\hline & & & & \multicolumn{2}{|c|}{ (unit : 10 hours) } \\
\hline Hours Farm size & O 3.0. $5^{\prime \prime \prime}$ & $0.5-1.0^{\text {ha }}$ & $1.0-1.5^{\mathrm{ha}}$ & $1.5-2.0 " ”$ & $2.0^{\text {ha }}$ over \\
\hline Actual hours & 157 & 303 & 447 & 543 & 692 \\
\hline Optimum hours & 163 & 295 & $45 \mathrm{G}$ & 583 & 667 \\
\hline
\end{tabular}

\section{Conclusions}

The recent mechanization of Japanese agriculture has been carried out through the introduction of power tillers. As the price of power tillers is very high relative to farm income, the mechanization of Japanese agriculture has been treated from the standpoint of non-economic reasons such as the demonstration effect. However, my opinion concerning mechanization differs from that of the non-economic interpretations mentioned above. Rather, it is my view that mechanization has resulted from the structural change which has occurred in the labor market. The Japanese economy has undergone a high rate of growth 
since 1955; consequently, the industrial sector has absorbed a considerable portion of laborers, thus giving rise to a labor shortage in the agricultural sector. If farmers wanted to work for other farms, they could do so without difficulty. There are always opportunities, either part-time labor work or renting out power tillers.

These conditions show that very near perfect competition exists in the markets for labor and in the rental of power tillers which serve to make Japanese agriculture operate economically and rationally. That is to say, it is operating on the principle of cost minimization for producing a given output. This behavior of the agricultural sector is exactly the same as the behavior of industrial enterprises and results in the maximum utility of farm households in the districts under review. I therefore conclude that the mechanization of Japanese agriculture is quite reasonable from the viewpoint of economic rationality.

\section{Mathematical appendix}

\section{A. Maximizing}

(1) $U=U(A, M)$, where $U_{A}<0, U_{M}>0,\left.\begin{aligned} & \partial^{2} M \\ & \partial A^{2}\end{aligned}\right|_{U=\text { const. }}>0$

subject to

( 2 ) $\tilde{y}=f(a, k)$, where $f_{a}>0, f_{k}>0, \frac{\partial^{2} a}{\partial k^{2}}>0$

( 3 ) $M=P_{y} \tilde{y}+\mathrm{W}(\mathrm{A}-\mathrm{a})+\boldsymbol{P}_{k}(\bar{K}-k)$

forms the function

(1A) $\pi=U(A, M)-\lambda_{1}\{f(a, k)-\tilde{y}\}-\lambda_{2}\left\{M-W(A-a)-P_{k}(\bar{K}-k)-P_{y} \tilde{y}\right\}$

where $A, a, k$ and $M$ are unknown variables to be solved, $\tilde{y}, k, W$ and $P_{k}$ are parameters, $\lambda_{1}$ and $\lambda_{2}$ are Langrange multipliers.

The first order conditions require that the first partial derivatives of $\pi$ must vanish for both maxima and minima. This condition gives,
(2A) $\frac{\partial \pi}{\partial a}=-\lambda_{1} \partial f-\lambda_{2} W=0$
(3A) $\frac{\partial \pi}{\partial k}=-\lambda_{1} \frac{\partial f}{\partial k}-\lambda_{2} P_{k}=0$
(4A) $\frac{\partial \pi}{\partial A}=\frac{\partial U}{\partial A}+\lambda_{2} W=0$
(5A) $\frac{\partial \pi}{\partial \bar{M}}=\frac{\mathrm{aU}}{\partial M}-\lambda_{2}=0$ 
(2) $\frac{\partial \pi}{\partial \lambda_{1}}=\tilde{y}-f(a, k)=0$

( 3 ) $\left.\frac{\partial \pi}{\partial \lambda \underline{a}}=P_{y} \tilde{y}+W(A-a)+P_{k} \overline{(K}-k\right)-M=0$

The last two equations ensure that the constraint are satisfied.

$\boldsymbol{a}, \boldsymbol{A}, \boldsymbol{K}$ and $M$ are obtained as solutions of the above simultaneous equations and have been substituted in the above equations.

( 6 A ) $\frac{\partial \pi^{*}}{\partial a}=-\lambda_{1}^{*} f_{a}^{*}-\lambda_{2}^{*} W=0$

(7A ) $\frac{\partial \pi^{*}}{\partial k}=-\lambda_{1}^{*} f_{k}^{*}-\lambda_{2} * P_{k}=0$

( $8 \mathrm{~A}) \frac{\partial \pi^{*}}{\partial A}=\frac{\partial U^{*}}{\partial A}+\lambda_{2} * W=0$

(9A) $\frac{\partial \pi^{*}}{\partial M}=\frac{\partial U^{*}}{\partial M}-\lambda_{2}^{*}=0$

$(10 \mathrm{~A}) \quad \frac{\partial \pi^{*}}{\partial \lambda_{1}}=\tilde{y}-f\left(a^{*}, k^{*}\right)=0$

(11A) $\frac{\partial \pi^{*}}{\partial \lambda_{, 2}}=P_{y} \tilde{y}+W\left(A^{*}-a^{*}\right)+P_{k}\left(K-k^{*}\right)-M^{*}=0$

where $f^{*}=f\left(a^{*}, k^{*}\right)$ and so on. From above equations we can derive as follows :

(12A) $\quad U_{M}^{*}=\lambda_{W} *>0$

(13A) $\quad \lambda_{1}^{*}=-\frac{\lambda_{2}^{*} W}{f_{a}^{*}}<0$

$\partial f^{*}$

(14A) $\frac{\overline{\partial a}}{\partial f^{*}}=\frac{f_{a}^{*}}{f_{k}^{*}}=-\frac{W}{P_{k}}$

$\partial k$

$(15 \mathrm{~A})-\frac{U_{A}^{*}}{U_{M}^{*}}=W$

So, second order condition is satisfied $a^{*}, A^{*}, k^{*}$, and $M^{*}$ are optimum solutions and they are equivalent to the quantity, utility maximum.

B. Minimizing

(6) $\mathrm{C}=W a+P_{k} k$

subject to

(2) $\bar{y}=f(a, k)$ 
Following step is formed

(1B) $\pi^{\prime}=W a+P_{k} k-\lambda_{3}\{f(a, k)-\tilde{y}\}$

where a, $\mathbf{k}$ are unknown variables to be solved, $\tilde{y}$, Wand $P_{k}$ are parameters. $\lambda_{3}$ is Langrange multiplier. The first order conditions require that the first partial derivatives of $\pi^{\prime}$ must vanish for both maxima and minima,

$$
\frac{\partial \pi^{\prime}}{\partial a}=\mathbf{W}-1, \quad \frac{\partial f}{\partial a}=0
$$

(3B) $\frac{\partial \pi^{\prime}}{\partial k}=P_{k}-\lambda_{3} \frac{\partial f}{\partial k}=0$

(4B) $\frac{\partial \pi^{\prime}}{\partial \lambda_{3}}=\tilde{y}-f(\mathrm{a}, \mathbf{k})=\mathbf{0}$

The solution of the above simultaneous equations are obtained as $\boldsymbol{a}^{0}$, $k^{0}$ and $\lambda_{3}^{0}$. If we substitute them into the above equations, the following equations are obtained.

( $5 \mathrm{~B}$ ) $W-\lambda_{3}{ }^{0} f_{a}{ }^{0}=0$

(6 B ) $P_{k}-\lambda_{3}{ }^{0} f_{k}{ }^{0}=0$

(7 B ) $\bar{y}-f\left(a^{0}, k^{0}\right)=0$

From above equations we can derive as follows :

(8B) $\lambda_{3}{ }^{0}=\frac{W}{f_{a}{ }^{0}}>0$

(9B) $\frac{f_{a}^{0}}{f_{k}^{0}}=\frac{W}{P_{k}}$

As second order condition is satisfied, a" and $k^{0}$ are equivalent to the input level of the minimum cost to produce a given output. As (a" and $\left.\mathbf{k}^{\prime \prime}\right)$ and $\left(\mathrm{a}^{*}\right.$ and $\left.k^{*}\right)$ are the solutions of the same simultaneous equations (2) and (4), both solutions are exactly of the same quantity.

\section{References}

1. Kayo, N., 1963. Nihon Nogyo no kikaika no kadai (The Problems of Mechanization in Japanese Agriculture), Nosei Chosa Iinkai.

2. Kudo, Z., 1962. An Economic Study of the Farm Machinery on a Japanese Family Farm. Tohoku Nogyo Shikenjo Hokoku (Bulletin of the Tohoku National Agricultural Experimental Station), October, No. 25.

3. Nakajima, C., 1958. An Equilibrium Theory of the Farm Household. Gendai Nogyo Bunseki no Tenbo (A Survey of Contemporary Agricultural Economics), 
Ohkawa, K. and Kawano, S., eds., Taimeido.

4. Nakajima, C., 1966. The Utility Function of Farm Households. Noringyo Mondai Kenkyu (The Study of Agriculture and Forestry), vol. 2, No. 1.

5. Tanaka, O., 1967. Nogyo no Kinko Bunseki (Agricultural Equilibrium Analysis), Yuhikaku.

6. Tsuchiya, K., 1969. Economics of Mechanization in Small Scale Agriculture. Agriculture and Economic Growth: Japan's Experience, Ohkawa, K., Johnston, B. F. and Kaneda, H., eds., Tokyo University Press and Princeton University Press. 